\title{
HarvestChoice
}

\section{Supporting Strategic Investment Choices in Agricultural Technology Development and Adoption}

\section{CO-PRINCIPAL INVESTIGATORS \\ Jawoo Koo and Philip Pardey}

\section{Overview}

HarvestChoice began in 2006, when detailed and readily accessible data on agriculture, human welfare, and the environment were scarce for Africa South of the Sahara (SSA). Statistics to support agricultural policy and investment decisions in the region were often too coarse-available only at national scale. Since then, technology advances (e.g., remote sensing, geographic information systems, and modeling tools) have enabled rapid data generation.

For supporting policy and strategic investment decision making, data products need to be well-documented with meaningful metadata, ground-truthed, focused, flexible, and consistent, as well as timely and geographically relevant for multiple users and for multiple scenarios. Cross-disciplinary data, for example from socioeconomics and the natural sciences, must be interoperable and, ideally, spatialized, if we are to capture the complexity of agriculture, people and place. To this end, HarvestChoice's primary goal was to spearhead the development of new, standardized, spatially-explicit data layers relevant for SSA agriculture, harmonized from multiple data sources-which included rescuing and repurposing statistical data from previously inaccessible formats. A second goal of HarvestChoice was to make sense of these data and help inform strategic decisions regarding technical change in SSA agriculture. To do this, HarvestChoice developed suites of tools both to enable data users to explore, summarize, 
and visualize our core datasets and to draw on these data to conduct bio-economic analyses in support of decision making in SSA agriculture. To date, more than 300 published journal articles used HarvestChoice's data as the basis of their study ${ }^{1}$.

In addition to its data products, in partnership with key collaborators, HarvestChoice delivered a collection of flagship knowledge and analysis products-including new (bio-economic) models, data documentation, analyses, and an extensive series of on-line and written reports and policy digests. These knowledge products are clustered around the core theme of Realizing the Potential of African Agriculture. Most of this work focused on the spatial dimension of African agriculture, with emphasis on the bioeconomy of agricultural production. Many of the policy- and investment-focused analyses draw insights from a unique juxtaposition of carefully harmonized, spatially explicit data assets developed by HarvestChoice and its partners.

\section{THE LANDSCAPE OF AFRICAN AGRICULTURE}

Agriculture is quintessentially a location-sensitive undertaking, both with respect to agricultural production per se and farmers' access to input and output markets. Thus, a comprehensive understanding of the location and character of African farming and its accessibility to markets is of immense value for a whole host of policy intervention and investment reasons. In this group of studies, we drew on an entirely new compilation of data to provide an integrated look at the contemporary landscape of farming in Africa and its relationship to off-farm markets.

\section{Where Crops Grow}

Given the important agricultural production and food access implications of geographical location, precisely where in the world crops are grown matters. Just as population is spread unevenly around the world, so too is agricultural production. With some exceptions, at the geographical scale of a country there is a reasonably close congruence between the location of people and the location of production. However, production and people are much less spatially congruent at more granulated (i.e., pixelated) geographical units. The biological basis of agriculture means that spatially variable factors like soil, climate, and pest and disease pressures play an important role in shaping the geography of global crop production along with spatially sensitive economic factors, including access to markets, the absolute and relative prices of inputs and outputs, and the policy environment within which agricultural markets operate.

\section{Procured Input Use in African Agriculture}

The development and analysis of a newly compiled dataset containing 55 variables on agricultural input use drawn from more than one million surveyed (farm) households spanning 257 first-level administrative units (ADM1) in 25 countries revealed the most comprehensive (and spatially calibrated) insights to date on input use in African agriculture. The use of mechanical traction services throughout SSA is still extremely limited, with just 5.9 percent of the surveyed farms in 8 countries reporting any tractor use. A substantial share (25.4 percent) of the farms still rely on animal traction, and 75.3 percent use manual labor. Inorganic fertilizer and improved seed use are still comparatively limited, both in the extent of their uptake and their geographical coverage, but with emerging indications of somewhat more expansive use. We find that one quarter (24.8 percent) of the surveyed farms (in 13 countries, 150 ADM1s) used inorganic fertilizer, while almost one-third (32.2 percent) of the farms (in 9 countries,

\footnotetext{
${ }^{1}$ For the full list of journal articles that use HarvestChoice data, see https://mendeley.com/community/who-uses-harvestchoice-data.
} 
84 ADM1s) used improved seed varieties. Importantly, our data reveal large spatial variation in the extent of use of all these procured inputs. For example, looking at the distribution of fertilizer use around the 24.8 percent whole-of-sample (150 ADM1) average, we find that 46 (30.7 percent) of these ADM1s reported that no more than five percent of their farms used inorganic fertilizers, whereas 30 (20 percent) of the ADM1s reported that at least 50 percent of their farms used fertilizer.

\section{Climate and Poverty}

The spatial dimension of poverty is a critical element of global development efforts. To properly address the root causes of extreme poverty, there is a growing need to identify the major areas of indigence and to understand their determinants. We expanded the existing knowledge on poverty determinants by drilling beneath the country-level statistics to quantify and assess the subnational distribution of welfare, both at the household- and district-levels. Specifically, we examined how climatic and environmental conditions affect income distribution after controlling for household level characteristics, to shed light on the likely role of climate change in affecting poverty and resilience in SSA, especially among the poorest. Our study takes advantage of a unique and innovative household level dataset containing information from nationally representative household surveys of 26 Sub-Saharan African countriesmore than one third of the entire African population and half the rural population in SSA. Econometric analysis revealed the substantial role of climatic conditions when it comes to explaining the distribution of household and district level welfare, as well as the likelihood of falling into moderate poverty, especially extreme poverty in rural areas. These results have important policy implications, as they show that climate change will mostly affect people already at the bottom of the welfare distribution, therefore calling for more supportive interventions to increase resilience.

\section{From Farm to Market}

Increasing market participation is critical for economic growth and poverty reduction, especially for small-scale farmers. Since market participation is tied to the transaction costs of accessing these markets, the location of farms and their physical and economic proximity to markets have a whole host of agricultural production and consumption implications that profoundly affect the economic circumstances of farm families. Understanding the spatial nuances of these potential transaction costs helps tailor future strategies aimed at transforming agriculture. Using a new, spatially explicit, compilation of economic-distant-to-market estimates, HarvestChoice analyses reveal a sizable but varying time-to-market disconnect between where agriculture takes place and the small towns and growing cities where increasing amounts of agricultural consumption is projected to occur. The average travel time in SSA to a market of 20,000 people is 6.8 hours and nearly half of regional crop value is located beyond three hours of travel. To get to markets farmers travel along roads of varying quality, and many farms are situated distant from roads. Our new evidence shows a critical "last kilometer" problem, with 60 percent of the SSA cropped pixels located in areas where at least half the travel time to markets of just 20,000 people is spent travelling off road. 
Panel a: Total travel time

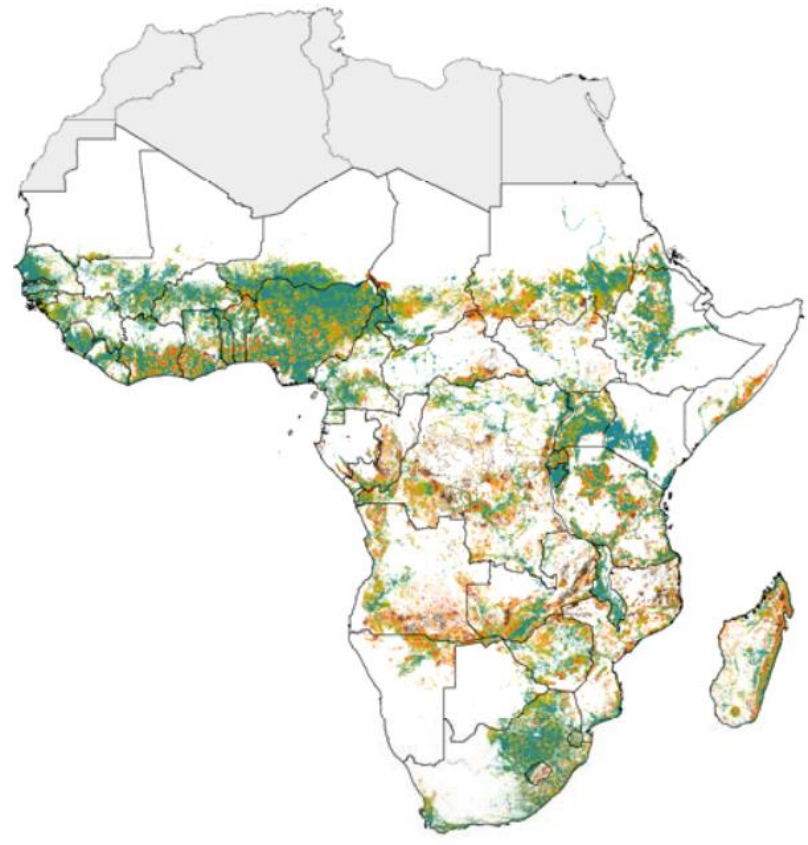

Travel Time (hours) $\square 0-3 \square>3-6 \square>6-12 \square>12-24 \square>24$
Panel b: Off-road travel time

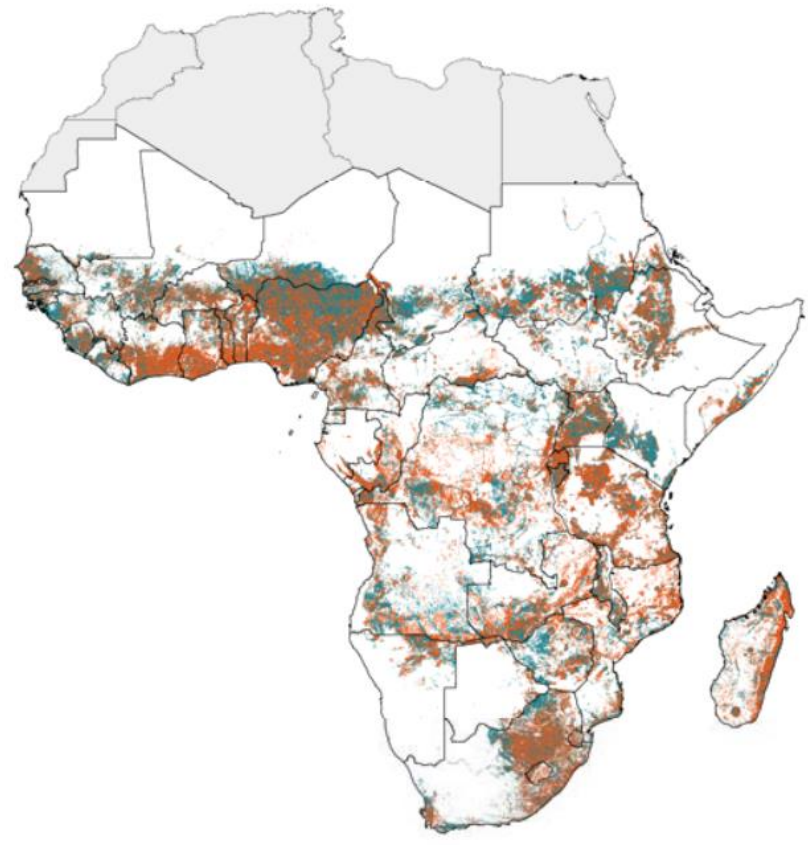

Off-Road Travel (percent of total) $=0-50 \square>50-100$

Maps of travel time to a market of at least $20 \mathrm{~K}$ people.

Source: Joglekar \& Pardey (2016). https://ageconsearch.umn.edu/record/253951

\section{Learn More}

- Azzarri, C., Bacou, M., Cox, C. M., Guo, Z., \& Koo, J. (2016). Subnational socio-economic dataset availability. Nature Climate Change, 6(2), 115-116. https://www.nature.com/articles/nclimate2842

- Sebastian, Kate, Ed. (2014). Atlas of African agriculture research and development: Revealing agriculture's place in Africa. Washington, D.C. International Food Policy Research Institute (IFPRI). http://dx.doi.org/10.2499/9780896298460

D Joglekar, A. B., Pardey, P.G., \& Wood-Sichra, U. (2016). Where in the World are Crops Grown? Retrieved from https://ageconsearch.umn.edu/record/253950

- Azzarri, C., \& Signorelli, S. (2020). Climate and poverty in Africa South of the Sahara. World Development, 125, 104691. https://doi.org/10.1016/j.worlddev.2019.104691

D Joglekar, A. B., \& Pardey, P. G. (2016). Proximity to African Agricultural Markets, Down to the Last Kilometer. Retrieved from https://ageconsearch.umn.edu/record/253951 


\section{THE GEOGRAPHY OF AFRICAN AGRICULTURAL PRODUCTION AND PRODUCTIVITY}

Our studies in this series focus on the geography of crop production and the relationship between location and productivity. Using new results of the HarvestChoice Spatial Production Allocation Model (MapSPAM; https://mapspam.info), we conducted a suite of spatial analyses, focused on important staple crops and regions. Building on the model documentation and assessment on the robustness of the MapSPAM methods and results, we prepared policy-relevant interpretations of these spatial production data. In briefing notes, we applied and interpreted the MapSPAM 2005 results, with an emphasis on benchmarking African agriculture vis-à-vis agriculture in other regions. Going beyond a detailed 2005 snapshot of spatial production realities, we also assembled, spatialized and analyzed historical data to examine the past (and thereby prospective) changes in the in the footprint of African maize production to assess the production, productivity and technology cum market implications of movements in the location of African agriculture.

\section{Shifting Geography of Maize Production in Africa}

This first look at the long-run spatial movement of maize production in selected African countries during the 20th century revealed that, while the area under maize production expanded substantially over time, there has also been a remarkable shift in the location of maize production both between and within countries. This has profound implications for the types of maize technologies that are relevant for African agriculture given site-specific variation in the biotic and abiotic factors that influence maize yields. This study also shows that spatial yield distributions change over time, and there is considerable variation in the pattern of that change among countries.

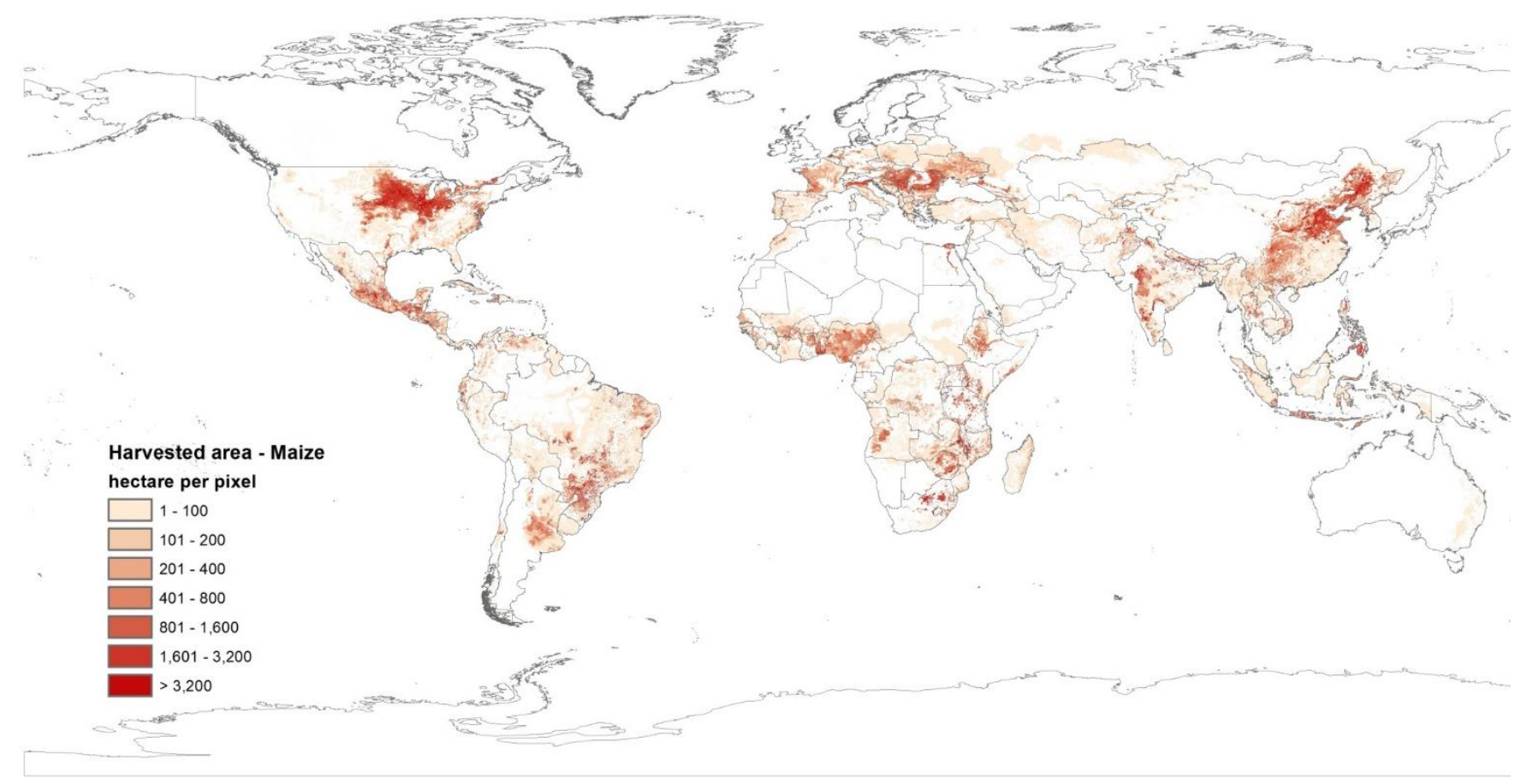

Global harvested area of maize circa 2005. Source: MapSPAM 2005 by HarvestChoice. https://doi.org/10.7910/DVN/DHXBJX 


\section{Fragmented Farms}

Household agricultural production not only affects the welfare of individual rural families, but also food supplies on a global scale. Likewise, agricultural productivity hinges largely upon farmers' choice of technology, inputs, and management strategies. Land fragmentation is a common farming practice worldwide, occurring when contiguous plots of land are farmed as a single production unit, resulting in fragmentation and spatial separation of the plots in a farm. Land fragmentation can be beneficial to farmers by diversifying risk onto separate land plots with heterogeneous growing conditions. Using Tanzanian household survey data, we found robust evidence to support a risk-reduction hypothesis, indicating a positive association between land fragmentation and production efficiency. Modelling showed land fragmentation may encourage risk-averse farmers to increase labor intensity, thereby leading to higher efficiency.

\section{Never Mind the Yield Gap}

Using empirical evidence and economic logic, a HarvestChoice study concludes that closing yield gaps are the wrong objective if the primary concern is improve food security outcomes, which is fundamentally about the capacity of agriculture to supply affordable food efficiently and sustainably to subsistence farmers and nonfarm consumers alike. Closing yield gaps is neither necessary nor sufficient for improving food security outcomes. We demonstrated how a region's overall yield and output can improve even though (spatial) yield gaps are increasing. Further, targeting the closure of yield gaps as a policy objective to feed more people may have unintended consequences. For example, idling either less-productive land (thus decreasing the gap directly) or idling the most productive land (thus reducing the limiting yield) would close the yield gap, but would also reduce total output. Output is the primary determinant of the availability and affordability of food, and efforts to increase output will tend to improve the lot of non-farmers as well as farmers. Thus, in many cases, policies might best be focused on increasing the output of a region or the world via investments that enhance farmer productivity and participation in markets rather than on simply decreasing yield gaps.

\section{Learn More}

Wood-Sichra, U., Joglekar, A.B., \& You, L. (2016). Spatial production allocation model (SPAM) 2005: Technical documentation. HarvestChoice Working Paper. Washington, D.C. https://www.ifpri.org/publication/spatial-production-allocation-model-spam-2005technical-documentation

- Rao, X. (2018). Land fragmentation with double dividends - the case of Tanzanian agriculture. European Review of Agricultural Economics, 46(4), 609-635. https://doi.org/10.1093/erae/iby034

Beddow, J. M., Hurley, T. M., Pardey, P. G., \& Alston, J. M. (2014). Food Security: Yield Gap. In N. K. Van Alfen (Ed.), Encyclopedia of Agriculture and Food Systems (pp. 352-365). https://doi.org/10.1016/B978-0-444-52512-3.00037-1 


\section{CONSTRAINTS ON AFRICAN CROP PRODUCTION}

Studies in this group are focused on the biotic and abiotic constraints confronting farmers in Africa, and the implications for targeting productivitypromoting interventions in African agriculture. An entirely new, spatially-explicit, suite of crop pest and disease geographies was developed and assessed, and the overall biotic production risk exposure of African maize, wheat and cassava farmers was quantified. For the biotic constraints, we developed new models of 23 pest and disease species that affect wheat, maize, and cassava. These models allow us to characterize the climatic suitability for pest survival both between and within seasons worldwide spatially. For the abiotic constraints, we have developed a new, spatiallyexplicit, production risk indicator, founded in economic theory. Our indicator is constructed specifically to yield directly actionable policy insights and investment strategies related to climate risk.

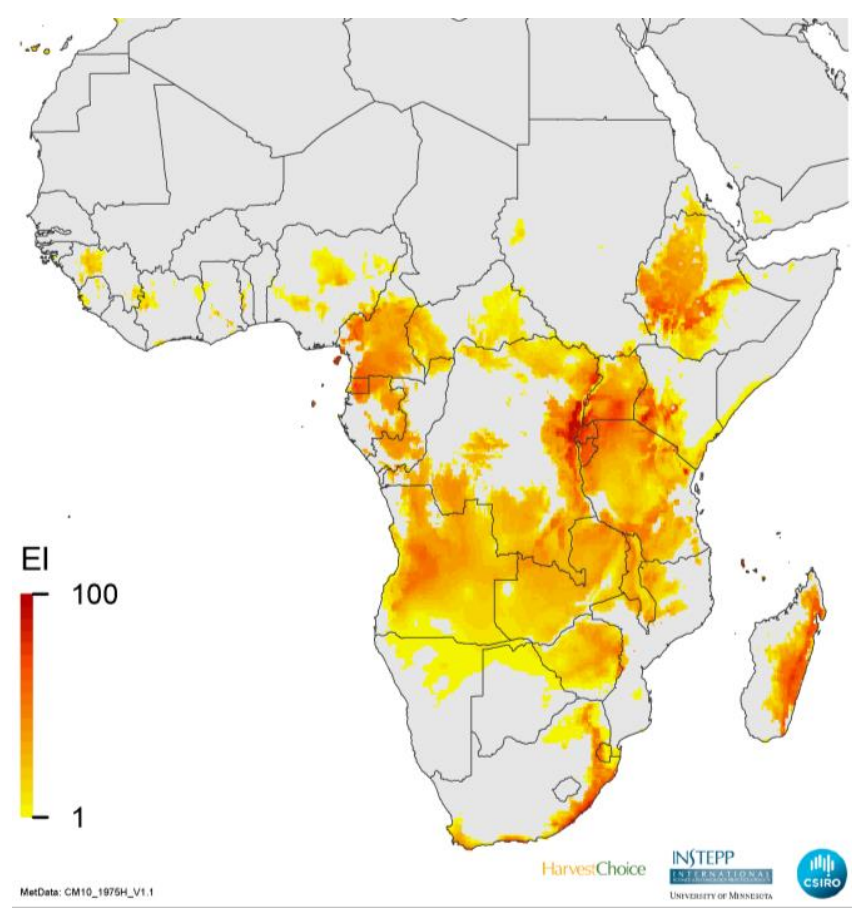

Modeled climate suitability for wheat stem rust in SSA with only natural rainfall. Source: Beddow et al. (2015) https://www.instepp.umn.edu/products/puccinia-graminis

\section{Spending for Healthy Wheat Crops Worldwide}

Breeding new crop varieties with resistance to the biotic stresses that undermine crop yield and quality is essential to promoting and preserving agricultural production. However, the success of genes that confer resistance to pests induces a co-evolutionary response, as pests evolve the capacity to overcome the crop's new defenses. Thus, simply maintaining this biological capital from agriculture, and the beneficial production and economic outcomes it bestows, requires continual reinvestment in new crop defenses. We developed and implemented a new, spatially explicit, probabilistic approach to assessing the bio-economic consequences of stem, leaf and stripe rust in wheat worldwide, and analyzed the implications for investments in rust-reducing R\&D. Looking at stripe rust, for example, we documented a significant increase in the spatial spread of this disease since 1960 , with $88 \%$ of the world's wheat production now susceptible to infection. Using our probabilistic Monte Carlo simulation model, we estimate that 5.47 million tons of wheat are lost to the pathogen each year, equivalent to a loss of 979 million USD per year. Comparing the cost of developing stripe-rust-resistant varieties of wheat with the cost of stripe-rust-induced yield losses, we estimate that a sustained annual research investment of at least 32 million USD into stripe rust resistance is economically justified.

\section{Multi-peril Pest Risks and the Geography of Crop Production}

Most prior analyses of crop pest pressures take a pest-by-pest approach, and many focus exclusively on the biology of the problem, ignoring important economic implications. But farmers and crop breeders alike are juggling the crop yield and other tradeoffs involved in simultaneously mitigating the effects of a whole host of pests and diseases. HarvestChoice pioneered the development of a portfolio of spatially explicit pest suitability estimates worldwide (including SSA) and the application of new, multi-peril, bioeconomic risk assessment methods to better inform breeders and farmers. Geospatial assessment of 
multi-pest risk to maize, wheat, and cassava production in SSA from a suite of 23 important agricultural pests and diseases revealed that crop-specific pest hotspots are, perhaps unsurprisingly, coincident with biomes that are well known biodiversity hotspots. The majority of SSA maize and cassava production takes place in regions that are jointly suitable for many of the maize and cassava pests that we analyzed (specifically at least seven out of the eleven maize pests we examined, and three out of four cassava pests). Conversely, much of SSA wheat production occurs in regions that are jointly suitable for only a few wheat pests. These results have important policy implications in terms of what types of risk management strategies can provide the greatest benefits to farmers depending on what crops are being grown and where they are being grown.

\section{Poor Soil Quality Threatens Sustainable Food Production}

Using satellite imageries to map land cover of Northern Ghana from 1994 to 2014, and applying spatial regression analysis, we examined the relationship between land cover change, current productivity, and harvest value. Through the construction of a unique dataset combining information from georeferenced household surveys, remote sensing, and other secondary data sources, we introduced a unique method to observe the relationship between landscape-level transformations and household-level outcomes. Areas that are currently cultivated but were covered by vegetation in 1994 showed higher agricultural production and productivity than areas that were previously bare soil. This suggests the expansion of crop land into degraded areas with poor soil fertility may not yield expected positive gains, thus threatening the sustainability of agricultural production upon which millions of poor smallholders rely.

\section{Sustaining the Benefits of Nitrogen Fertilizer and Improved Seeds with Weather Risk}

While the benefits of nitrogen tend to increase overtime without improved seed varieties, the benefits of improved seed varieties tend to decrease overtime without added nitrogen. Thus, improving both seed varieties and nutrient applications is important for promoting sustained productivity increases. Our novel analysis found a synergy between nitrogen fertilizer and improve seed varieties, with the combination of both providing more sustained productivity performance. Therefore, securing both fertilizer and improved variety adoption is important for promoting sustained productivity increases across most of SSA. From a policy perspective, securing higher adoption levels of both can be most effectively obtained by sequentially introducing farmers to improved seed varieties before encouraging the use of nitrogen fertilizer, because farmers are more (a)

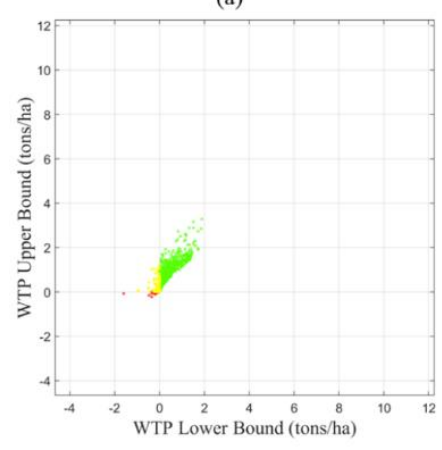

(b)

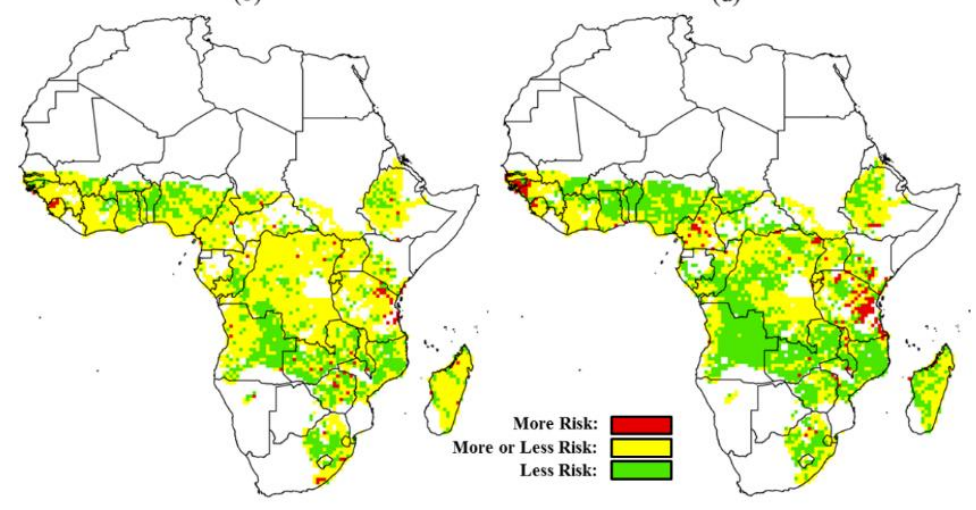

Traditional variety with versus without $40 \mathrm{~kg}[\mathrm{~N}] / \mathrm{ha}$ fertilizer in year 1 $(a, b)$ and 10 years after adoption $(c, d)$.

Source: Hurley et al. (2018) https://doi.org/10.1111/agec.12454 
likely to see larger improvements faster and with less additional effort from improved seed. The novel geospatial analysis used to obtain these insights establishes bounds on what farmers' willingness to pay for access to improved seed, nitrogen fertilizer or both in light of their risk aversion. The method is also broadly applicable to evaluating a wide range of technology decision farmers may face where risk (e.g., from weather, markets, pests, or diseases) is an important consideration.

\section{Trade and Resilience Building}

Biophysical risks associated with climate change, if unmitigated, would, in the long run, erode the capacity of countries to use trans-border trade to stabilize domestic food markets-highlighting the intricate relationship between ecosystem resilience and food system resilience, and the role of trade in linking the two. While trade can enhance food system resilience to current ecosystem shocks, such shocks, if persistent and severe enough, would gradually undermine the ability of food systems to absorb them. In other words, trade can at best offer temporary relief from the effects of climate shocks. Strategies to enhance food system resilience should therefore consider trade as an important part of a broader agenda to fight climate shocks and reduce their impacts on production systems.

\section{Learn More}

INSTEPP, University of Minnesota. (2016). Crop Pest Geography. https://www.instepp.umn.edu/crop-pest-geographies

Pardey, P. G., J. M. Beddow, D. J. Kriticos, T. M. Hurley, R. F. Park, E. Duveiller, R. W. Sutherst, J. J. Burdon and D. Hodson (2013). "Right-Sizing Stem-Rust Research." Science 340(6129): 147. https://doi.org/10.1126/science.122970

- Senay, S. D. and S. P. Worner. (2019). "Multi-Scenario Species Distribution Modeling." Insects 10(3): 65. https://doi.org/10.3390/insects10030065

Haile, B., Signorelli, S., Azzarri, C., \& Guo, Z. (2019). A spatial analysis of land use and cover change and agricultural performance: evidence from northern Ghana. Environment and Development Economics, 24(1), 67-86.

https://doi.org/10.1017/S1355770X18000323

Hurley, T., Koo, J., \& Tesfaye, K. (2018). Weather risk: how does it change the yield benefits of nitrogen fertilizer and improved maize varieties in sub-Saharan Africa? Agricultural Economics, 49(6), 711-723. https://doi.org/10.1111/agec.12454

Azzarri, C., Piras, G., Roberts, C., Koo, J. Guo, Z., \& Gong, Q. (2014). Regional trade flows and resilience in COMESA and ECOWAS countries. In ReSAKSS Annual Trends and Outlook Report 2013. http://ebrary.ifpri.org/cdm/ref/collection/p15738coll2/id/128852 


\section{AFRICAN AGRICULTURAL INNOVATION: HISTORY AND PROSPECTS}

Drawing on newly updated and expanded $R \& D$ spending and returns-to-research databases from the University of Minnesota InSTePP (https://instepp.umn.edu), and a new genetics and genomics global patent database, we conducted a comprehensive and up-to-date assessment of various dimensions of the African agricultural innovation landscape. This exercise will provide BMGF and others with a quantitative sense of the rapidly evolving $R \& D$ investment and innovation realities facing sub-Saharan Africa as a guide to future investment strategies.

\section{Faltering Agricultural Research and Development Investments in SSA}

Research-enabled growth in agriculture is pivotal to overall economic growth prospects of SSA, yet investments in research and development (R\&D) targeted to national food and agricultural economies are fragile and faltering throughout Africa. These investment trends are in stark contrast with the newly updated evidence on the economic returns to agricultural R\&D, which indicate the considerable social payoffs to increasing investments in R\&D. The 399 reported internal rates of return (IRRs) to food and agricultural research in or for SSA averaged $42.3 \%$ per year for studies published in the period 19752014, while the corresponding 129 benefit-cost ratios averaged 30.1 . Most (96.5\%) of the returns-toresearch evaluations are of publicly performed $R \& D$.

\section{The Landscape of Genetic and Genomic Patenting in SSA vis-à-vis the Rest of the World}

Patent families (that track the patenting of a particular invention in multiple jurisdictions) provide a unique empirical window into the shape and nature of flows of intellectual property from one country or region (such as SSA) to others. Using a newly compiled global set of data on families of genetics and genomics related patents in health and agriculture for the period 1971-2000, we reveal that the balance of intellectual trade on genetic and genomics inventions between sub-Saharan Africa and the rest of the world is clearly one of net imports. We see hints in the patenting data that foreign filings into subSaharan Africa are part of families larger than average, and thus sub-Saharan African jurisdictions tend to play host to fewer yet stronger patents than their higher-income peers. There is outward IP flow as well: the patent system is also providing opportunities for elite inventors in sub-Saharan Africa to protect their inventions in both other developing countries, in large emerging economies, and even in high-income economies.

\section{Learn More}

Pardey, P. G., R. S. Andrade, T. M. Hurley, X. Rao and F. G. Liebenberg (2016). "Returns to food and agricultural R\&D investments in Sub-Saharan Africa, 1975-2014." Food Policy 65: 1-8. https://doi.org/10.1016/j.foodpol.2016.09.009

Graff, G. D. and P. G. Pardey (2020). "Inventions and patenting in Africa: Empirical trends from 1970 to 2010." The Journal of World Intellectual Property 23(1-2): 40-64. https://doi.org/10.1111/jwip.12139 


\section{ABOUT THE AUTHORS}

Jawoo Koo is Senior Research Fellow of the Environment and Production Technology Division at the International Food Policy Research Institute (IFPRI).

Philip G. Pardey is Professor of Science and Technology Policy in the Department of Applied Economics at the University of Minnesota.

\section{TEAM MEMBERS}

Carlo Azzarri, Melanie Bacou, Jason Beddow, Yuan Chai, Connie Chan-Kang, Maria Comanescu, Cindy M. Cox, Susana Crespo, Queenie Gong, Chris Gray, Zhe Guo, Beliyou Haile, Michelle Hallaway, Terrance Hurley, Alison Joglekar, Frikkie Liebenberg, Xudong Rao, Cleo Roberts, Ivy Romero, Senait Senay, Apurba Shee, Sara Signorelli, Ria Tenorio, Stanley Wood², Ulrike Wood-Sichra, and Liangzhi You.

\section{COLLABORATORS}

Robert Andrade, Ainsley Charles, Elizabeth Cross, Will Cuddy, Jeffrey Dickinson, John Dimes, Etienne Duveiller, Gregory Graff, Joseph Green, Jan C. Greyling, Jubal Harpster, Kendall Hauptfleisch, Robert Hijmans, Patrice Howard, Nanga Kaye, Steve Kibet, Maction Komwa, Darren Kriticos, Chris Legg, lan Luby, Robert Mabagala, Eduardo Magalhaes, Cecile Martignac, Grant McKenzie, Maxwell Mkondiwa, Panagiotis Mylonas, Kelly Nail, Erick Nkonya, Noboru Ota, Andrew Petran, Gianfranco Piras, Nathaniel Robinson, Nome Sakane, Pascale Schnitzer, Kate Sebastian, Asif Shaikh, Todd Slind, Jonathan Speiser, Robert Sutherst, Kindie Tesfaye, Cecilia Tinonin, T. Kelly Turkington, Elodie Valette, Stephen R Waddington, Ojo Williams, Tania Yonow, and Biwen Zhou.

\section{ACKNOWLEDGMENTS}

Funding support for all of the HarvestChoice work was provided by the Bill and Melinda Gates Foundation, CGIAR Research Program on Policies, Institutions, and Markets, and the University of Minnesota.

\section{DEDICATION}

We dedicate this project note to the memory of Jason Beddow, Frikkie Liebenberg, and Eduardo Magalhaes.

\footnotetext{
${ }^{2}$ Stanley Wood served as a Co-PI from 2006 to 2012, after which Jawoo Koo took over as a Co-PI.
} 


\section{Explore HarvestChoice's Flagship Data and Tool}

- HarvestChoice Dataverse (https://dataverse.harvard.edu/dataverse/harvestchoice), an open-access repository of HarvestChoice-generated geospatial datasets, including CELL5M (750 multidisciplinary biophysical and socio-economic indicators) and MapSPAM (spatially-disaggregated crop production statistics data).

- African Agriculture Data Rescue Initiative (https://www.instepp.umn.edu/africanagriculture-data-rescue-initiative), a collection of digitized agricultural statistics data, covering 47 variables from 36 sources for 24 countries spanning 231 first-level subnational administrative units for the period 1993-2013.

Data Africa (https://dataafrica.io), a Webby award-winning data visualization platform that provides information on agriculture, climate, poverty and child health across 13 SSA countries at the sub-national level.

This publication has been prepared as an output of the HarvestChoice project and has not been independently peer reviewed. Any opinions expressed here belong to the author(s) and are not necessarily representative of or endorsed by IFPRI. 